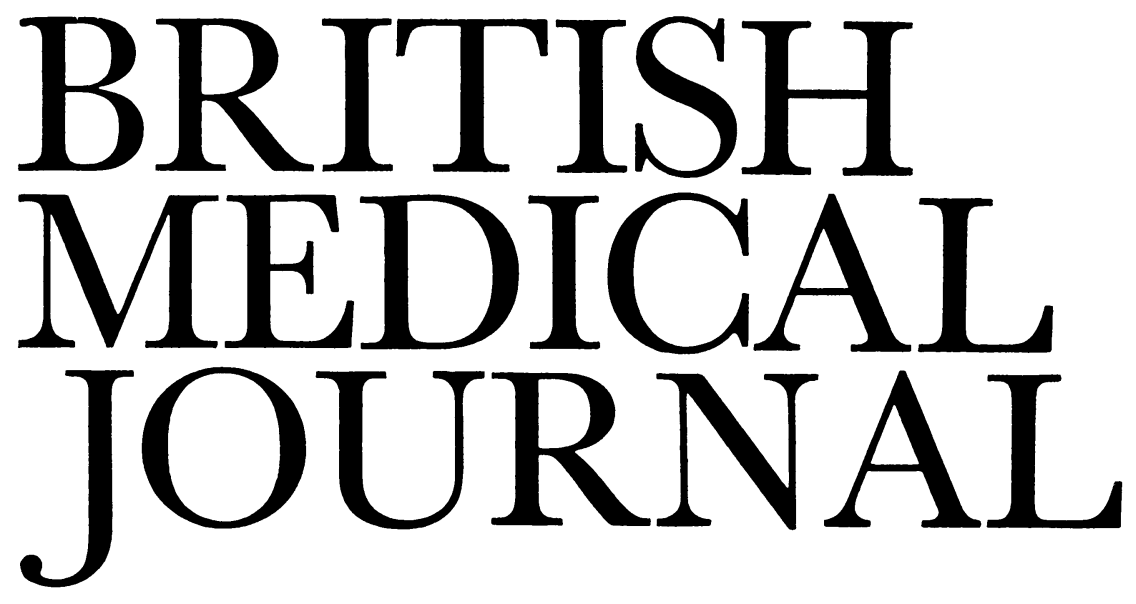

\title{
Spina bifida and anencephaly: fewer patients, more problems
}

Anencephaly and spina bifida aperta occur when the neural tube fails to develop normally and are the most striking of the common malformations. Ever since the pioneering studies of Record and McKeown ${ }^{12}$ it has been evident that the birth prevalence of these defects-the number of affected infants born, dead or alive, expressed as a proportion of all live births and stillbirths - varies widely and that these variations are broadly similar for the two defects. ${ }^{34}$ Some of the variations-for example, those observed with sex, family relationship, and colour-may be due to genetic factors. Othersnotably differences in liability between first born and other children of the same families, and trends over space and time in populations of apparently similar genetic composition-are probably related to the prenatal environment.

These genetic and environmental influences may produce their effects by affecting either the proportion of embryos which become malformed (incidence) or the proportion of malformed embryos which result in spontaneous abortion. Most of the effects that have been studied appear to reflect differences in incidence, though the available evidence is limited. ${ }^{4}$ Accordingly it is widely believed that many genes and environmental factors affect development of the neural tube. In each individual embryo it is suggested that these effects add up to a score, and that neural tube defects arise in those whose score exceeds a critical threshold. ${ }^{5}$

Three questions have recently emerged from the continued surveillance of the prevalence of defects of the neural tube and the search for specific environmental factors which might influence this prevalence. Firstly, is the recent decline in birth prevalence the result of improved antenatal screening and termination of pregnancy? Secondly, can sodium valproate cause spina bifida? Thirdly, what further tests are needed of the hypothesis that the intake of vitamins affects prevalence?

On the first point, prevalence began to decline in England and Wales after 1972. The national notification rate fell between 1972 and 1981 from 1.47 per thousand live births and stillbirths to 0.39 for anencephaly, and from 1.88 to 1.04 for spina bifida. ${ }^{6}{ }^{7}$ Defects of the neural tube also seem to have become less common in Northern Ireland, ${ }^{8}$ the United States, ${ }^{910}$ and Australia, ${ }^{11} 12$ though in these countries the reduction has been less striking than in England and Wales. The reduction has been greater for anencephaly than for spina bifida except in parts of the United States.
One piece of evidence for screening programmes being the main sources of this decline in prevalence is a report that in the Irish Republic, where there is no antenatal screening programme, the decline has been negligible. ${ }^{13}$ On the other hand, the increasing number of terminations of pregnancy reported from Britain and Australia is insufficient to account for more than a small part of the decline in these countries, ${ }^{8121415}$ while in the United States the decline started well before 1970 in the absence of screening. ${ }^{91016}$ In the Netherlands the prevalence of anencephaly has fallen fairly consistently since the 1950 s. $^{17}$ In more recent years periods of stable prevalence in Britain and the north eastern United States have been preceded as well as followed by substantial changes-for example, a rise in the prevalence of anencephaly and spina bifida during the early 1950s and a fall during the next decade in England. ${ }^{15}$ These earlier trends also suggest that antenatal screening is not the only factor behind the recent decline-in which case this decline will have reduced the cost effectiveness of screening.

On the second point, the anticonvulsant drug sodium valproate is teratogenic in rodents. ${ }^{18}$ In a recent report from France spina bifida was described in three tenths of 30 malformed children born between 1976 and 1982 with a history of exposure to sodium valproate in the first trimester of pregnancy. This figure was nearly 15 times the corresponding number for children with no exposure to the drug. Similar inquiries elsewhere in Europe and America yielded comparable findings in one population but no cases of spina bifida after exposure to the drug in six others, data which fail to clarify the problem, since these populations did not seem to have used much sodium valproate. ${ }^{19}$ In yet another group of children with congenital malformations born to mothers taking sodium valproate, nine out of 39 had spina bifida. ${ }^{20}$ Both reports suggest that either the diagnosis of spina bifida has been sought and confirmed more assiduously than other malformations in children exposed to the drug or that the proportion of malformed children who have spina bifida is indeed higher after exposure to sodium valproate. With other anticonvulsant drugs, by contrast, the proportion of malformed children with oral clefts and congenital heart disease is increased. ${ }^{21}$ But it is not the frequency of spina bifida among malformed children but its frequency among all children after exposure to sodium valproate that most needs to be explored. 
For this the published data are insufficient, and we must await studies in which normal as well as malformed births to takers and non-takers of sodium valproate are fully represented. Meanwhile, women who have taken the drug in early pregnancy should perhaps be offered an amniocentesis to check the concentration of $\alpha$-fetoprotein in the amniotic fluid.

The third and most contentious question concerns the hypothesis that vitamin supplements during pregnancy prevent defects of the neural tube. Other publications ${ }^{22} 23$ have reviewed the observations which support this hypothesis: evidence from studies in animals, experience with the use of drugs which are antagonists of folic acid, seasonal and social class variations in prevalence and nutrition, correlations between the outcome of pregnancy and concentrations of vitamins in the blood in early pregnancy, and, finally, the apparent success of two clinical trials of vitamin supplements given in the periconceptional period to women who had previously produced affected children. Even these trials, however, do not prove conclusively that vitamin supplements prevent defects of the neural tube. In the first trial, a double blind comparison of folic acid and a placebo, the difference in the outcome of pregnancy was not statistically significant. ${ }^{24}$ The second study, using a combination of folate and other vitamins, was not a randomised controlled trial and compared women who accepted vitamins before conception with those who either declined them or who were already pregnant. ${ }^{25}{ }^{26} \mathrm{~A}$ further limitation of this trial was that it could not indicate which specific vitamin, if any, might prevent congenital defects.

Because of these limitations the Medical Research Council is launching a further trial in mothers of affected children who wish to conceive again. Participants will be randomly distributed among four groups to receive pills in which minerals will either be the only active ingredients or be combined with folate, with other vitamins, or with both. ${ }^{27}$

This trial is intended to show whether vitamin supplements can reduce the recurrence rates of defects of the neural tube to the extent suggested by the second trial (about sixfold). It will succeed, however, only if there is no great decline in "natural" recurrence rates and if the intended number of participants-at least 2000 -can be recruited and then restrained from taking other vitamin preparations. It will be surprising if all these provisions are satisfied. With the current decline in prevalence we may expect recurrence rates to fall, since the two tend to vary concordantly. ${ }^{4829}$ Even more important, any normal mother of an affected child who is told (as potential participants must be) that vitamin supplementation may possibly prevent recurrence and that entering the trial may mean forgoing such treatment will surely decline to participate. Her family doctor will probably back this decision, especially since the advice recently proffered in the $B M \mathcal{F}$ was that "folate should be given to any woman with a .. . history of a child with spina bifida or anencephaly" who wishes to conceive..$^{30} \mathrm{~A}$ more practicable and ethical way to reassess whether or not vitamin supplements reduce recurrence rates might be to look at how these rates have changed in the recent past. In periods and places in which vitamin supplements have been widely used one would expect to find a lower overall recurrence rate than elsewhere if supplementation were really effective, but not if the differences observed between supplemented and unsupplemented pregnancies were due only to self selection.

IAN LECK

Professor of Community Medicine, University of Manchester, Manchester M13 9PT
1 Record RG, McKeown $T$. Congenital malformations of the central nervous system: I. A survey of 930 cases. British fournal of Social Medicine $1949 ; 3: 183-219$.

${ }^{2}$ McKeown T, Record RG. Seasonal incidence of congenital malformations of the central nervous system. Lancet $1951 ; \mathrm{i}: 192-6$.

${ }^{3}$ Elwood JM, Elwood JH. Epidemiology of anencephalus and spina bifida. Oxford: Oxford University Press, 1980.

4 Leck I. Epidemiological clues to the causation of neural tube defects. In: Dobbing J, ed. Prevention of spina bifida and other neural tube defects. London: Academic Press, 1983:155-82.

5 WHO Scientific Group on Genetic Factors in Congenital Malformations. Genetic factors in congenital malformations. WHO Tech Rep Ser 1970 ; No 438.

${ }^{6}$ Rogers SC, Weatherall JAC. Anencephalus, spina bifida and congenital hydrocephalus: England and Wales, 1964-1972. London: HMSO, 1976. (Studies on medical and population subjects, No 32.)

${ }^{7}$ Office of Population Censuses and Surveys. Congenital malformations. London: HMSO, 1982. (OPCS Monitor, MB3 82/3, 82/4.)

${ }^{8}$ Nevin NC. Neural tube defects. Lancet 1981 ;ii:1290-1.

${ }^{9}$ Stein SC, Feldman JG, Friedlander M, Klein RJ. Is myelomeningocele a disappearing disease? Pediatrics 1982;69:511-4.

10 Windham GC, Edmonds LD. Current trends in the incidence of neural tube defects. Pediatrics 1982;70:333-7.

${ }^{11}$ Field B, Kerr C, Mathers CD. Incidence of neural-tube defects. Dev Med Child Neurol 1982;24:861-2.

${ }^{12}$ Danks DM, Halliday JL. Incidence of neural tube defects in Victoria, Australia. Lancet 1983;i:65.

${ }^{13}$ Kirke P. Epidemiological clues to the causation of neural tube defects: discussion. In: Dobbing J, ed. Prevention of spina bifida and other neural tube defects. London: Academic Press, 1983:191-2.

14 Owens JR, Harris F, McAllister E, West L. 19-Year incidence of neural tube defects in area under constant surveillance. Lancet 1981 ;ii:1032-5.

15 Leck I. Epidemiological clues to the causation of neural tube defects: discussion. In: Dobbing J, ed. Prevention of spina bifida and other neural tube defects. London: Academic Press, 1983:185-7.

16 Janerich DT. Epidemic waves in the prevalence of anencephaly and spina bifida in New York State. Teratology 1973;8:253-6.

${ }^{17}$ Romijn JA, Treffers PE. Anencephaly in the Netherlands: a remarkable decline. Lancet $1983 ; \mathrm{i}: 64-5$.

${ }^{18}$ Brown NA, Kao J, Fabro S. Teratogenic potential of valproic acid. Lancet 1980;i:660-1.

19 Bjerkedal T, Czeizel A, Goujard J, et al. Valproic acid and spina bifida. Lancet 1982;ii:1096.

${ }^{20}$ Jeavons PM. Sodium valproate and neural tube defects. Lancet 1982 ;ii 1282-3.

${ }^{21}$ Smithells RW. Environmental teratogens of man. Br Med Bull 1976;32: 27-33.

${ }^{22}$ Anonymous. Spina bifida: controversy over tests continues. Nature 1982;300:396-7.

${ }^{23}$ Dobbing J, ed. Prevention of spina bifida and other neural tube defects. London: Academic Press, 1983.

${ }^{24}$ Laurence KM, James N, Miller MH, Tennant GB, Campbell $H$. Double-blind randomised controlled trial of folate treatment before conception to prevent recurrence of neural-tube defects. $\mathrm{Br} \mathrm{Med} \mathcal{J}$ $1981 ; 282: 1509-11$.

${ }^{25}$ Smithells RW, Sheppard S, Schorah CJ, et al. Apparent prevention of neural tube defects by periconceptional vitamin supplementation. Arch Dis Child $1981 ; 56: 911-8$.

${ }^{26}$ Smithells RW, Nevin NC, Seller MJ, et al. Further experience of vitamin supplementation for prevention of neural tube defect. Lance $1983 ; \mathrm{i}: 1027-31$

${ }^{27}$ Wynn J. Spina bifida: trials ahead. Nature $1982 ; 299: 198$.

${ }^{28}$ Yen S, MacMahon B. Genetics of anencephaly and spina bifida ? Lancet 1968;ii :623-6.

29 Nevin NC. Recurrence risk of neural tube defects. Lancet 1980;1:1301-2.

${ }^{30}$ Bull MJV. Pregnancy. Br Med f 1982;284:1611-2.

\section{Pregnancy in patients with prosthetic heart valves}

Patients who have had palliative or corrective cardiac surgery for congenital or acquired heart disease are being seen increasingly often as candidates for antenatal cardiac care. Cardiac surgery is usually not curative and each such patient requires individual assessment. The chances of success depend on their haemodynamic state, the effects of pregnancy on this and on fetal development, the likelihood of thromboembolic or infective complications, the possible effects on the child of 